\title{
Flood Risk Perception in the Housing Market and the Impact of a Major Flood Event $\partial \square$
}

\author{
Hannah Hennighausen Ph.D. student, Wegener Center for Climate and Global Change, Department of \\ Economics, University of Graz, Graz, Austria; hannah.hennighausen@uni-graz.at \\ Jordan F. Suter Associate professor, Department of Agricultural and Resource Economics, Colorado State \\ University, Fort Collins; jordan.suter@colostate.edu
}

\begin{abstract}
The impact of flood events on flood risk perception has important implications for policy. Applying a novel dataset featuring the flooding extents from a severe event in Colorado, we disentangle inundated properties from "near misses," defined as structures not directly flooded but located inside the 100-year floodplain. Using a triple-difference hedonic framework, we show that inundated properties inside the floodplain underwent a decrease in price after the flood, while near misses saw a relative price increase. We speculate that inundated properties are perceived as being riskier and near misses relatively less risky, suggesting the possible influence of the availability heuristic or Bayesian learning. (JEL Q54, Q58)
\end{abstract}

\section{Introduction}

Floods are the most common natural disaster type worldwide. Between 1995 and 2015, 2.3 billion people were affected by floods, considerably more than any other type of natural disaster event (CRED 2015). In the United States alone, flooding causes $\$ 6$ billion in property damage in an average year (USGS 2006). Approximately $7 \%$ of all land in the United States is designated as having a significant level of flood risk (Holway and Burby 1990), and development in these risky areas explains some of the high costs associated with flooding.

In this paper we consider the impact of the National Flood Insurance Program (NFIP) on flood risk perception in Boulder County, Colorado. The overall aim of the NFIP is to

Land Economics • August 2020 - 96 (3): 366-383

ISSN 0023-7639; E-ISSN 1543-8325

(C) 2020 by the Board of Regents of the

University of Wisconsin System reduce the socioeconomic impact of flooding by identifying flood hazards, encouraging sensible floodplain management, and requiring flood insurance for mortgaged properties in the areas at greatest risk of flooding (FEMA 2016). Within a difference-in-differences framework, we estimate the influence of flood hazard mapping and a flood insurance buy-requirement on property sale prices before and after a major flood event. After including inundation of the property as a moderating variable, the results show that the extent to which flood insurance mandates are realized in the selling price of a property after a flood event depends on whether the property was directly flooded. As economic development in high flood risk areas continues, our results raise questions in the broader discussion of how individuals view the probabilities and consequences of flooding, particularly when the risks are experienced directly.

Previous studies have largely shown that price gaps exist across flood hazard zones, suggesting that home buyers respond to flood insurance mandates and/or risk information. In general, a property located in the riskiest floodplain has been shown to sell at a discount of $4 \%$ to $12 \%$ relative to an equivalent property outside the risky area (Harrison, Smersh, and Schwartz. 2001; Schultz and Fridgen 2001; Meldrum 2015). In a meta-analysis, Beltrán, Maddison, and Elliot (2018) estimated a $4.6 \%$ price discount associated with 100 -year floodplains in inland areas.

Broadly speaking, the price differential after a flood event increases, signifying a change in flood risk perception from the provision of new information (Skantz and Strickland 1987; Bin and Polasky 2004; Carbone, Hallstrom, and Smith 2006). Bin and Landry (2013) show that prices in the riskiest floodplain designation dropped $6 \%$ to $22 \%$, recov- 
ering only 7 to 9 years after the flood, while Daniel, Florax, and Rietveld (2009) find even longer lasting postflood impacts on property prices. One study finds that the dampening effect was also realized in areas close to, but not impacted by, the given flood event (Hallstrom and Smith 2005).

Moving beyond the majority of previous research, we incorporate spatially explicit data featuring the flooding extents from a major flood event in Boulder County, Colorado, in 2013. We are able to identify structures that were directly flooded (henceforth described as inundated) and estimate their risk capitalization in combination with flood risk zone designation and associated flood insurance mandates. By including inundation as a moderating variable, we are joining a small, yet growing body of work focused on disentangling the impact that direct flooding has on risk capitalization from a flood simply occurring in a nearby area (McCoy and Zhao 2018; Ortega and Taşpinar 2018; Beltrán, Maddison, and Elliot 2019). In particular, our empirical model makes it possible to compare the risk capitalization of inundated and noninundated properties inside the risky floodplain, as well as inundated properties outside the floodplain. Accordingly, the "pure information effect" from location in the risky floodplain can be differentiated from the "inundation effect" (Atreya and Ferreira 2015).

The NFIP encourages efficient decision-making by identifying properties with elevated flood risk, with the aim of reducing the information asymmetry between perceived risk by individuals and the Federal Emergency Management Agency's (FEMA's) own risk assessment. In the wake of a flood event, understanding the extent to which perceived flood risk aligns with FEMA's assessment of the risk can help policy makers to know where and how they should target their flood risk awareness campaigns to reduce and insure at-risk capital. Motivated by the fact that over half of the properties in Boulder County designated by FEMA as being at significant risk were not directly flooded in 2013, this paper addresses the following research question: How does inundation affect the sales prices of properties inside the regulatory floodplain?
The primary feature of this study that distinguishes it from the extant literature on flood risk perceptions in the housing market is the use of detailed geospatial data of flooding extents. In combination with building footprint locations, we account for heterogeneous price impacts within the floodplain due to flood-induced damages and/or differences in postflood risk perception. This study builds on recent work by Meldrum (2015) that does not find a statistically significant flood risk discount for single-family homes in Boulder County for the 20 years prior to the flood event. We further explore flood risk capitalization using more recent data that span a major flood event in the county and allow us to better understand the heterogeneity associated with changes in flood risk capitalization after the event.

This work most closely aligns with work by Atreya and Ferreira (2015) and Ortega and Taşpinar (2018). Their papers are among the only hedonic studies that we are aware of to explicitly estimate the impact of inundation separately from a property being located in a designated flood-prone area. Like this one, the two studies employ a difference-in-differences methodology. Ortega and Taşpinar focus on hurricane-induced damage, using Hurricane Sandy and New York City as their case study. They show that damaged and not-damaged properties located in areas with high flood risk underwent a price decrease following Hurricane Sandy, with the former undergoing a more dramatic loss in value immediately after the event. Our treatment of inundated properties in the econometric model more closely follows the approach by Atreya and Ferreira. These researchers focus on the property markets in Albany, Georgia, before and after the Great Flood of 1994, showing that inundated properties in the floodplain were subject to a more dramatic postflood price decrease than properties that were not inundated but are also located in the floodplain. Our work adds to this limited set of studies in several dimensions. The Boulder County housing stock and flood hazard are considerably different from those of both New York City and Albany, Georgia. Boulder County has a mix of urban, suburban, and rural properties. It is also more affluent with a newer housing stock compared to the relatively stagnant housing market in Albany. 
Moreover, given that the Boulder County flood event was a riverine flood, the type and extent of property damage is different from the case of Hurricane Sandy.

The empirical results that were obtained using a hedonic, triple-difference framework show that properties inside the risky floodplain in Boulder County (defined as the Special Flood Hazard Area [SFHA] or 100-year floodplain) sold for a $6.5 \%$ discount prior to the flood. The magnitude of the discount is generally in line with what has been found in previous studies. After the flood, areas that were "nearly missed" by the flood waters no longer sold for a significant discount. In contrast, properties that were both inundated and located in the riskiest floodplain underwent a relative decrease in price, selling at a $21 \%$ discount.

We offer two possible explanations for the diverging price impacts within the regulatory floodplain. The first is that home buyers were influenced by the availability heuristic, whereby individuals overestimate the probability of events that come to mind very easily (Tversky and Kahneman 1973). For example, after the flood, home buyers in the near-miss areas may have overestimated the probability that they would be missed by any future flooding in the county, despite the fact that they were still located inside the regulatory floodplain. Alternatively, it may be that home buyers were following a Bayesian learning model, observing where the flooding took place and rationally updating their expectations (Viscusi 1991; Gallagher 2014). If the flooding extents better represent true flood risk than the flood hazard maps put forth by FEMA, then the relative price increase experienced by the near misses may have been efficient.

\section{Background}

\section{The NFIP}

Through the early twentieth century, flood risk and recovery were managed via a combination of federal and private initiatives. The U.S. federal government provided funds for structural control measures (such as levees and dams) as well as disaster relief funds on a disaster-by-disaster basis, while private flood insurance providers filled the risk gaps. The private insurance market ceased to exist following the great Mississippi flood of 1927, and flood insurance was not available to homeowners for the next several decades (American Institutes for Research 2005). Even with government incentives, the high concentration and correlation of risks associated with floods made flood insurance unattractive to private insurers (Michel-Kerjan 2010).

The NFIP was crafted in the 1960s in response to the rising costs of ad hoc postdisaster relief legislation, America's first billion-dollar hurricane, significant population growth in flood-prone areas, as well as the influential voice of prominent geographer Gilbert White (American Institutes for Research 2005). White helped design the NFIP and, together with the Task Force on Federal Flood Policy, emphasized in their reports that flood insurance must serve two purposes: (1) offer financial relief to those impacted by flood events and (2) have influence on land use and its development (or restriction thereof) (White 1958).

The NFIP is a voluntary partnership between the federal government and local communities. By law, FEMA cannot offer flood insurance to communities that do not meet the minimum floodplain management regulations as designated by the NFIP. FEMA and communities work together to map flood hazards, partitioning the landscape into three flood risk zones: the SFHA, also called the 100-year floodplain ( $1 \%$ or greater chance of flooding per year), as well as the 500-year floodplain (0.99\%-0.2\% chance of flooding per year), and the floodplain of minimal flood risk. The three categories add up to $100 \%$ of habitable land. Flood maps, called Flood Insurance Rate Maps (FIRMs), identify these areas and are intended to create awareness of the hazard as well as help states and communities plan floodplain development (FEMA 2016). Flood hazard data provided by the FIRMs are freely and publicly accessible.

The NFIP also provides a basis for flood insurance buy-requirements and rates. With the passage of the Flood Disaster Protection Act of 1973, flood insurance coverage became mandatory for all properties located in the 
Table 1

Flood Insurance Premiums for Single Family Pre- and Post-FIRM SFHA Properties (Dollars)

\begin{tabular}{lccccc}
\hline $\begin{array}{l}\text { Building } \\
\text { Coverage }\end{array}$ & $\begin{array}{c}\text { Contents } \\
\text { Coverage }\end{array}$ & $\begin{array}{c}\text { Pre-FIRM } \\
\text { Annual } \\
\text { Premium }\end{array}$ & $\begin{array}{c}\text { Pre-FIRM } \\
\text { Premium } \\
\text { NPV }\end{array}$ & $\begin{array}{c}\text { Post-FIRM } \\
\text { Annual } \\
\text { Premium }\end{array}$ & $\begin{array}{c}\text { Post-FIRM } \\
\text { Premium } \\
\text { NPV }\end{array}$ \\
\hline 20,000 & 8,000 & 297 & 9,900 & 481 & 16,033 \\
30,000 & 12,000 & 446 & 14,867 & 721 & 24,033 \\
50,000 & 20,000 & 743 & 24,766 & 1,202 & 40,067 \\
75,000 & 30,000 & 1,121 & 37,367 & 1,488 & 49,600 \\
100,000 & 40,000 & 1,509 & 50,300 & 1,550 & 51,667 \\
125,000 & 50,000 & 1,897 & 63,233 & 1,612 & 53,733 \\
150,000 & 60,000 & 2,285 & 76,167 & 1,674 & 55,800 \\
200,000 & 80,000 & 3,061 & 102,033 & 1,798 & 59,933 \\
250,000 & 100,000 & 3,837 & 127,900 & 1,922 & 64,066 \\
\hline
\end{tabular}

Note: Rates calculated for properties without basements. Pre-FIRM rates are for valid properties built prior to the first floodplain regulations in 1969. Premium net present value (NPV) calculated into perpetuity assuming constant premium rates, yearly payments, and a discount rate of 3\%. Post-FIRM payments calculated assuming property has one flood and that the flood is at the same elevation as the base flood elevation. FIRM, Flood Insurance Rate Map; SFHA, Special Flood Hazard Area.

SFHA that held federally backed mortgages (American Institutes for Research 2005). For a single-family residence, the NFIP provides insurance up to a maximum limit of 250,000 dollars for building coverage and 100,000 dollars for contents coverage (FEMA 2018). The cost of the insurance premium increases with flood risk and property vulnerability (for example, properties with basements are more costly to insure). Table 1 presents an overview of NFIP premium costs, both yearly and the net present value of the sum of payments calculated into perpetuity. Properties built before the first FIRMs often carry subsidized rates, as indicated in the table. Nationally, one in four properties in the SFHA is eligible for a subsidized rate (GAO 2011). In Boulder County, nearly half of SFHA properties were built before the county's first flood risk map and, therefore, are potentially eligible for a subsidized rate.

\section{Boulder County Flood Risk}

Boulder County was among the first communities in the United States to adopt floodplain regulations, joining the NFIP at its inception (Pettem 2006). The county's flood risk is complex, mirroring the varied landscapes in the area. Streams have their headwaters in the high reaches of the Rocky Mountains, located in the western portion of the county.
The streams run eastward, passing through narrow and steep canyons, alongside small mountain towns and county roads, eventually emerging from the foothills. From there they flow through large population centers until they join the larger South Platte River. The sample of property transactions that we focus on in this study represents the more populated portion of the county that lies to the east of the foothills. Figure 1 depicts the flood hazard areas in the eastern Boulder County study area in relation to its populated areas. Nearly $3 \%$ of buildings are located inside the SFHA. Structures are at risk of flash flooding, alluvial fan flooding, and/or riverine flooding, depending on the surrounding topography. Historical records show that Boulder County has seen at least three large, damaging flood events in the last 150 years, with more regular, smaller events occurring in between (Pettem 2006; FEMA 2015).

The present study uses the Boulder County FIRM to identify buildings inside the SFHA and the 500-year floodplain. The FIRM was obtained via the National Flood Hazard Layer, a geospatial dataset created by FEMA. The Boulder County FIRM was last updated in 2004, nearly 10 years prior to the 2013 flood event. For half of the municipalities in the study area, we use building footprint data available on the city of Boulder's geospatial open data site. The remaining municipalities 
Figure 1

Study Area Flood Hazard, Exposure, and Risk

Flood Hazard

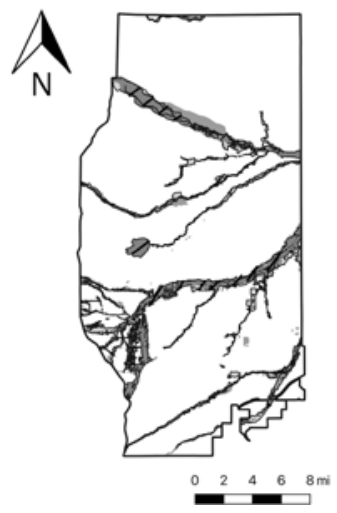

Flood Risk

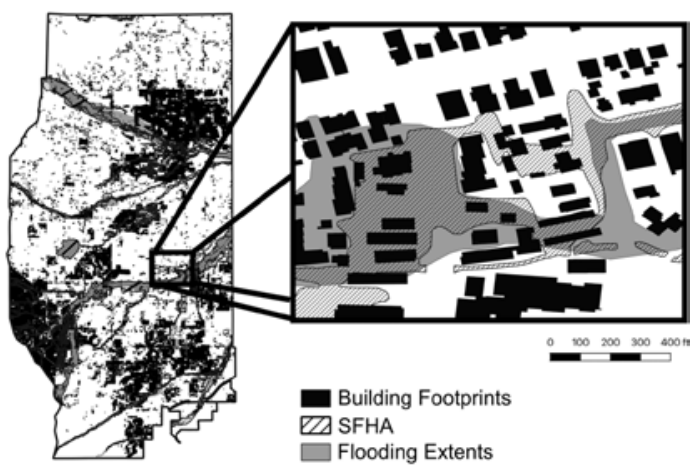

are filled in with Microsoft's Building Footprint Data, a computer-generated dataset spanning all 50 states. For the city of Boulder, Microsoft's machine-learning algorithm captures $90 \%$ of the buildings drawn by the city, with the remaining $10 \%$ likely reflecting difficulties because of complex topography and/or dense urban centers.

September 2013 brought devastating and widespread flash flooding to much of Colorado's Front Range urban corridor. With a range of almost 200 miles, the scope of the flooding was unprecedented for the state. The extraordinary characteristics of the 2013 Colorado flood led the National Weather Service to state that, in some areas, the amount of rainfall was considered a 1 in 1,000-year occurrence (Gochis et al. 2015). The flood resulted in a presidential disaster declaration for 18 Colorado counties, of which Boulder was among the hardest hit. Nearly $50 \%$ of FEMA's \$260 million in public assistance committed to the disaster was earmarked for Boulder County (FEMA 2015).

Flooding extent data are available on the geospatial open data sites for Boulder County and the city of Boulder and are presented in Figure 1. The inundated areas were drawn by the National Geospatial Agency, with supplemental information coming from Boulder County Land Use and Parks and Open Space using imagery from the Digital Globe First Look product. Multiple images, taken on different days, due to cloud cover, were used to determine the high-water mark. The dataset was further refined using damage assessment data points. The county saw $4 \%$ of structures inundated by the flood, of which $70 \%$ are located inside the SFHA. It should also be noted that nearly two-thirds of structures located inside the SFHA were not inundated.

\section{Empirical Strategy}

Environmental goods are not usually traded directly in markets. Real estate markets, however, provide an opportunity to observe revealed preferences for environmental characteristics (Palmquist 1982). The most commonly used technique to study the effects of environmental traits on property prices is the hedonic property model, whereby property prices are determined by a set of structural, neighborhood, and environmental characteristics (Rosen 1974).

Applying the hedonic regression to environmental amenities and dis-amenities in the housing market began with Ridker and Henning's (1967) pioneering contribution on the effects of air pollution on property prices. A long tradition of hedonic analysis in environmental economics has followed, with recent studies evaluating the impacts of proximity to open spaces (Walls, Kousky, and Chu 2015), beach erosion (Gopalakrishnan et al. 2011), climate change forecasts (Severen, Costello, and Deschenes 2018), wildfire risk (McCoy 
and Walsh 2018), and the Fukushima nuclear accident (Tanaka and Zabel 2018).

Following the empirical strategy of previous studies, we utilize a hedonic property model to investigate the capitalization of flood risk in the Boulder County real estate market. The model features the sales price of a given property as the dependent variable, regressed on structural attributes (e.g., square footage) as well as locational and environmental amenities (e.g., distance of the property from a body of water). As shown by Atreya, Ferreira, and Kriesel (2013), perception of the risk of flooding can also impact property prices. Location in the SFHA serves as a proxy for perceived flood risk realized through flood insurance mandates. We hypothesize that the impact of the SFHA variable depends on whether the property was sold before or after the 2013 flood. To test the hypothesis, we employ a difference-in-differences specification, designating location in the SFHA as the treatment. Year-quarter dummies $\tau_{t}$ control for time-specific shocks that are common to all observations. Similarly, census block group dummies $\left(v_{i}\right)$ and city dummies $\left(\mu_{i}\right)$ account for time-invariant spatial heterogeneity.

$$
\begin{aligned}
P_{i, t}= & \beta_{0}+\beta_{1} \mathrm{~S}_{i}+\beta_{2} \mathrm{~L}_{i}+\alpha_{1} \text { SFHA }_{i}+\alpha_{2} \text { Postflood }_{i, t} \\
& +\alpha_{3} \text { SFHAPostflood }_{i, t}+\tau_{t}+v_{i}+\mu_{i}+\varepsilon_{i, t} .
\end{aligned}
$$

Equation [1] serves as the base model, where SFHA is a dummy variable equal to one if property $i$ is located in the 100-year floodplain and zero otherwise. Similarly, Postflood is a variable equal to one if the sale occurred after the flood and zero if the sale happened before the flood. SFHAPostflood represents the postflood sale of a property in the SFHA. In the presence of the interaction term, the coefficients $\alpha_{1}$ and $\alpha_{2}$ are marginal effects and must be interpreted as holding the other variable equal to zero. For example, $\alpha_{1}$ is the impact of being located in the SFHA group prior to the flood. Similarly, $\alpha_{2}$ captures aggregate factors that caused postflood price changes even in the absence of a treatment group.

The difference-in-differences setup allows for the comparison of two groups, properties inside the SFHA and properties outside the SFHA, over two time periods: before and after the 2013 flood. In the simplest case, we observe that two identical properties, one treated (inside the SFHA) and one not, follow a common price trend in the absence of a flood event. If, however, we detect that the trends of the selling prices of the two properties diverge in the presence of flooding, the price wedge between the two is labeled as the impact of the flood. The difference-in-differences coefficient is $\alpha_{3}$ on the interaction term SFHAPostflood. By subtracting the average postflood price change in the control group from the average postflood price change in the treatment group, we are quite literally taking a difference in differences.

$$
\begin{aligned}
\hat{\alpha}_{3}= & \left(\bar{P}_{\text {SFHA,Postflood }}-\bar{P}_{\text {SFHA,Preflood }}\right) \\
& -\left(\bar{P}_{\text {NonSFHA,Postflood }}-\bar{P}_{\text {NonSFHA,Preflood }}\right) .
\end{aligned}
$$

Equation [1], the base model, does not permit model parameters to differ across inundated and noninundated zones. By including the dummy variable Inundated and its interaction PostfloodInundated, we constrain the model and allow intercepts to differ depending on whether a property was directly flooded, as shown in equation [3].

$$
\begin{aligned}
P_{i, t}= & \beta_{0}+\beta_{1} \mathrm{~S}_{i}+\beta_{2} \mathrm{~L}_{i}+\alpha_{1} \text { SFHA }_{i} \\
& +\alpha_{2} \text { Postflood }_{i, t} \\
& +\alpha_{3} \text { SFHAPostflood }_{i, t} \\
& +\phi_{1} \text { Inundated }_{i} \\
& +\phi_{2} \text { PostfloodInundated }_{i, t} \\
& +\tau_{t}+v_{i}+\mu_{i}+\varepsilon_{i, t} .
\end{aligned}
$$

We hypothesize that inundation of a property could have two effects. The first is that there are flood-induced changes to the structure that will be realized in the selling price of the property but are not picked up in the property-specific data provided by the county. The structural changes could be damage or damage and subsequent improvements, making the sign of the expected impact ambiguous. The second effect may be a flood-induced division within the floodplain to relatively "more risky" and relatively "less risky", assuming that changes in flood risk perception are restricted to the SFHA. For example, it may be that an inundated property located in the SFHA is perceived as a riskier investment 
than an identical but noninundated property also located in the SFHA.

Equation [3], while controlling for direct flooding, forces the average effect of the treatment, location in the SFHA, to be uniform regardless of whether a property was inundated or not. A more flexible analysis would see inundation as a moderating variable on the treatment. For this, a triple-difference specification is employed, as shown in equation [4].

$$
\begin{aligned}
P_{i, t}= & \beta_{0}+\beta_{1} \mathrm{~S}_{i}+\beta_{2} \mathrm{~L}_{i}+\alpha_{1} \text { SFHA }_{i}+\alpha_{2} \text { Postflood }_{i, t} \\
& +\alpha_{3} \text { SFHAPostflood }_{i, t}+\phi_{1} \text { Inundated }_{i} \\
& +\phi_{2} \text { PostfloodInundated }_{i, t} \\
& +\phi_{3} \text { SFHAInundated }_{i} \\
& +\pi_{1} \text { SFHAPostfloodInundated }_{i, t} \\
& +\tau_{t}+v_{i}+\mu_{i}+\varepsilon_{i, t} .
\end{aligned}
$$

The marginal effects are interpreted in the same way as in the difference-in-differences setup (equations [1] and [2]). For example, $\alpha_{2}$ is the postflood price effect of a property being located in neither the SFHA nor the inundation zone. Similarly, $\alpha_{3}$ is now the additional postflood price impact of being located in the SFHA but not in the inundation zone. We refer to such areas as "near misses," borrowing the term from Hallstrom and Smith (2005), referencing the fact that these properties, while officially located in risky areas, were not directly flooded. It follows that $\phi_{2}$ is the additional postflood impact of being located in the inundation zone but not in the SFHA, and $\pi_{1}$ is the marginal postflood impact of being both an SFHA property and located in the inundation zone. Figure 1 depicts the four mutually exclusive areas on a map of the study area.

The triple-difference estimate is defined as

$$
\begin{aligned}
\hat{\pi}_{1}= & {\left[\bar{P}_{\text {SFHA,Postflood,Inun }}-\bar{P}_{\text {SFHA,Preflood,Inun }}\right) } \\
& \left.-\left(\bar{P}_{\text {SFHA,Postflood,Noninun }}-\bar{P}_{\text {SFHA,Preflood,Noninun }}\right)\right] \\
& -\left[\left(\bar{P}_{\text {NonSFHA,Postflood,Inun }}-\bar{P}_{\text {NonSFHA,Preflood,Inun }}\right)\right. \\
& -\left(\bar{P}_{\text {NonSFHA,Postflood,Noninun }}\right. \\
& \left.\left.-\bar{P}_{\text {NonSFHA,Preflood,Noninun }}\right)\right] .
\end{aligned}
$$

The first term ( $\bar{P}_{\text {SFHA,Postflood,Inun }}-$ $\left.\bar{P}_{\text {SFHA,Preflood,Inun }}\right)$ is the average postflood price change for properties located in both the SFHA and the inundation zone. This is the primary outcome of interest. The three terms that follow net out potentially confounding trends. The second term represents general price trends specific to the SFHA $\left(\bar{P}_{\text {SFHA,Postflood,Noninun }}-\bar{P}_{\text {SFHA,Preflood,Noninun }}\right)$, the third term characterizes general price trends specific to the inundation zone $\left(\bar{P}_{\text {NonSFHA,Postflood,Inun }}-\bar{P}_{\text {NonSFHA,Preflood,Inun }}\right)$, and the last term is the general temporal price trend experienced by the entire study area $\left(\bar{P}_{\text {NonSFHA,Postflood,Noninun }}\right.$ $\left.-\bar{P}_{\text {NonSFHA,Preflood,Noninun }}\right)$. Dropping the second and fourth terms is the equivalent of restricting the sample to only the inundated areas and using a difference-in-differences setup to examine the postflood impact of location in the SFHA. Similarly, dropping the last two terms is the equivalent of subsetting the sample to only SFHA properties and examining the postflood impact of being inundated. Our aim is to determine the price impact of being located in both the SFHA and the inundation zone. Therefore, the triple-difference framework has an advantage over sample subsetting in that it controls for systematic differences within the entire inundation zone or SFHA not accounted for in the subsamples.

The focus of the present study is to identify the moderating impact that inundation has within the SFHA. In doing so, we are joining a small, yet growing, body of research. Hallstrom and Smith (2005) pioneered the literature by estimating risk capitalization in a coastal county that was narrowly missed by Hurricane Andrew. Using a repeat-sales model, the authors detected a decrease in SFHA property sales prices in the county after the hurricane. Both Atreya and Ferreira (2015) and Ortega and Tașpinar (2018) use maps, as we have done, to identify inundated properties. Atreya and Ferreira, using data from an area with significant flood risk, uncovered a significant discount associated with inundated properties within and outside the SFHA immediately following the flood, but no change was detected for noninundated properties located in flood risk areas. Ortega and Taşpinar focused on the New York City housing market in the aftermath of Hurricane Sandy, showing 
that both damaged and undamaged properties located in areas with high flood risk underwent a price decrease following the event.

\section{Data Description and Methods}

Structures located in the SFHA (as well as the 500-year floodplain) were identified by overlaying the FIRM for Boulder County on the building footprint dataset. ${ }^{1}$ Inundated structures were distinguished in the same way, using a map featuring the flooding extents. ${ }^{2}$

The sample of transactions that we used in the empirical analysis is limited to properties within one mile of the inundation boundary. Restricting the sample in this way is intended to promote the comparability between the treatment groups and control group. The choice is motivated by the regression discontinuity design literature, whereby samples are restricted around the targeted boundary to improve control over omitted variables that change smoothly over space (Black 1999). By doing this, the estimated impact of the boundary on the dependent variable is subject to less potential for bias from unobserved characteristics of geographic areas that are not accounted for by the census block group dummy variables and other control variables, in particular, exposure to any potential dis-amenity effects related to the flooding (McCoy and Walsh 2018; McCoy and Zhao 2018). For example, flood recovery construction that may have affected neighborhood traffic patterns should be similar. Appendix Figure A1 shows that our general conclusions also hold under the full sample, as well as subsamples within 0.5 miles and 1.5 miles of the inundation boundary.

\footnotetext{
${ }^{1}$ Federal Emergency Management Agency, FEMA Flood Map Service Center, available at https://msc.fema.gov/por tal/home. City of Boulder, Building Footprints, available at https://bouldercolorado.gov/open-data/city-of-boulderbuilding-footprints; Microsoft, U.S. Building Footprints, available at https://github.com/Microsoft/USBuildingFoot prints.

${ }^{2}$ City of Boulder, September 2013 Flooding Extents, available at https://bouldercolorado.gov/open-data/city-ofboulder-september-2013-flood-extents; Boulder County, Flood 2013 Inundated Areas, available at http://gis-boulder county.opendata.arcgis.com/datasets/a9624bd25d854ef7ab 0d543e9490ce48_0.
}

In Boulder County, the regulated floodplain is clustered alongside streams. These areas may also generally be associated with positive amenities such as favorable views and walking paths. For this reason, to isolate the floodplain price impact, it is critical to accurately control for a property's location close to a stream separately from its flood risk. We tested several variables representing the distance of the property to the closest waterway. Given the complexity of the terrain, we determined the best fit is achieved using four distance bands: 0 to 600 feet, 600 to 1,800 feet, 1,800 to 5,000 feet, and 5,000 to 8,000 feet from the closest perennially running stream. This is a similar strategy to that employed by Kousky (2010).

Property transaction data ${ }^{3}$ from the Boulder County Assessor's Office feature transaction date and price, structural characteristics including the number and type of rooms, the quality of the building ${ }^{4}$ (for which there are six level-categories), the age of the building, the number of finished square feet of the building, lot size, the presence of a finished basement, and the presence of car storage. ${ }^{5}$ The analysis was limited to single-family properties. Transactions with adjusted prices less than $\$ 50,000$ were removed to minimize the impact of nonarm's-length transactions. ${ }^{6}$ Observations with square footage less than 150 feet were also removed because of the high likelihood of

\footnotetext{
${ }^{3}$ Boulder County Assessor's property data download, available at https://www.bouldercounty.org/property-andland/assessor/data-download/.

${ }^{4}$ Building quality is potentially an endogenous variable for inundated properties. Appendix Tables A1 and A2 show that there was no significant change in the ratio of properties with very good quality and above sold inside the inundation boundary and regulatory floodplain. For inundated areas outside the regulatory floodplain, the ratio increased after the flood, suggesting that postflood changes in the risk discount associated with these properties could be viewed as an upper bound.

${ }^{5}$ Recent research (Bernstein, Gustafson, and Lewis, 2019) shows the relevance of housing tenure status associated with estimating risk discounts in property markets. While housing tenure information is not available for this case study, exploring differences in impacts, particularly when considering inundation, is an interesting area for future research.

${ }^{6}$ The results are robust to trimming the most expensive properties at the $1 \%(\$ 1,570,780)$ and $5 \%(\$ 867,890)$ cutoff levels.
} 
data entry error. The structural attributes were matched to the building footprint dataset via the associated parcels. Structural quality is presented as a dummy variable equal to one if the structure is characterized as having greater than very good quality. ${ }^{7}$

Maps from Boulder County, ${ }^{8}$ the Census Bureau, ${ }^{9}$ and the U.S. Geological Survey ${ }^{10}$ determined the distance of each parcel to lakes and reservoirs, open space, trailheads, and major roads, as well as each parcel's elevation and census block group. Census block group and municipality fixed effects are used to control for any additional spatial, time-invariant characteristics that may influence price. ${ }^{11}$

By limiting the analysis to the metropolitan area of Boulder County, we further avoided difficult-to-capture unobserved amenities associated with mountainous terrain. The metropolitan area is identified in the county's wildfire risk zone map as Zone 2 (Boulder County 2017). Eighty percent of the property transactions in the county during the study period were within the metropolitan area.

We selected the temporal window for our sample to exclude the 2008 downturn in the real estate market, beginning with observations in the third quarter of 2009. Moreover, our sample is balanced around the 2013 flood event, with four years of data on either side. Transactions occurring in the six weeks following the flood were excluded to minimize concerns related to discrepancies between the closing date of the sale and the actual sale date

\footnotetext{
${ }^{7}$ The results hold when including the full set of categorical quality variables.

${ }^{8}$ Boulder County, Open Data, available at http://gis-boul dercounty.opendata.arcgis.com/.

${ }^{9}$ U.S. Census Bureau, Cartographic Boundary Shapefiles: Block Groups, available at https://www.census.gov/ geo/maps-data/data/tiger-cart-boundary.html.

${ }^{10}$ U.S. Geological Survey, National Elevation Dataset (NED), available at https://www.usgs.gov/core-science-sys tems/national-geospatial-program/national-map.

${ }^{11}$ Both municipality and census block group fixed effects are included because some of the census block groups span (portions of) multiple municipalities. By including municipality fixed effects we account for time-invariant differences in municipality-level characteristics (even within the same block group) that affect housing prices. These include differences in zoning policies and services offered.
}

of the property. ${ }^{12}$ Year-quarter fixed effects account for time-variant unobservables common to all properties.

We estimated the models using ordinary least squares. While hedonic theory does not provide much guidance in the way of functional forms, we follow the majority of previous literature by using the natural log of price as the dependent variable because, compared to more complex forms, it gives relatively unbiased estimates in the face of omitted variables and performs well at estimating marginal price effects (Cropper, Deck, and McConnell 1988). The main results of the regressions are robust to most transformations of the explanatory variables; however, taking the natural log of the distance variables, lot size, and square footage, as well as the quadratic of age provides the best fit.

Table 2 provides descriptions and summary statistics for each variable in our subsample. Across all observations, the mean sales price for a property in the dataset is $\$ 424,036$. Just under $50 \%$ of the transactions took place after the flood. Nearly $4 \%$ of the properties sold are located in the SFHA, and 3\% are located within the inundation boundary. The proportion of properties sold inside the SFHA and the inundation zone remained relatively constant after the flood. Appendix Tables A1 and A2 provide summary statistics that are differentiated by treatment or control groups, before and after the 2013 flood.

\section{Empirical Results}

In this section we provide the empirical results for the econometric specifications introduced in Section 2, as well as evidence that assumptions for the causal interpretation of the difference-in-differences strategy are valid. The presentation of the econometric results focuses on the coefficient estimates that pertain to the flood risk variables, with the full results of the econometric models provided in the Appendix.

\footnotetext{
${ }^{12}$ The results are robust to keeping transactions six weeks after the flood in the sample.
} 
Table 2

Variables and Summary Statistics

\begin{tabular}{|c|c|c|c|c|c|}
\hline Variable & Description & Mean & Std. Dev. & Min. & Max. \\
\hline Price & Property sale price in unadjusted U.S. dollars & 424,036 & 284,924 & 50,000 & $4,724,509$ \\
\hline \multicolumn{6}{|c|}{1} \\
\hline SFHA & $\begin{array}{l}1 \text { if building is in the Special Flood Hazard } \\
\text { Area, } 0 \text { otherwise }\end{array}$ & 0.04 & 0.19 & 0 & 1 \\
\hline Postflood & $\begin{array}{l}1 \text { if sale occurred after the } 2013 \text { flood, } 0 \\
\text { otherwise }\end{array}$ & 0.47 & 0.50 & 0 & 1 \\
\hline Inundated & $\begin{array}{l}1 \text { if building is located inside the inundation } \\
\text { boundary, } 0 \text { otherwise }\end{array}$ & 0.03 & 0.17 & 0 & 1 \\
\hline $500 y r F P$ & $\begin{array}{l}1 \text { if building is in the 500-year floodplain, } 0 \\
\text { otherwise }\end{array}$ & 0.07 & 0.25 & 0 & 1 \\
\hline \multicolumn{6}{|l|}{ Location } \\
\hline Stream0to600ft & $\begin{array}{l}1 \text { if building is within } 600 \text { feet of a stream, } 0 \\
\text { otherwise }\end{array}$ & 0.09 & 0.28 & 0 & 1 \\
\hline Stream601to1800ft & $\begin{array}{l}1 \text { if building is between } 601 \text { and } 1,800 \text { feet of } \\
\text { a stream, } 0 \text { otherwise }\end{array}$ & 0.24 & 0.43 & 0 & 1 \\
\hline Stream1801to5000ft & $\begin{array}{l}1 \text { if building is between } 1,801 \text { and } 5,000 \text { feet } \\
\text { of a stream, } 0 \text { otherwise }\end{array}$ & 0.20 & 0.40 & 0 & 1 \\
\hline Stream5001to8000ft & $\begin{array}{l}1 \text { if building is between } 5,001 \text { and } 8,000 \text { feet } \\
\text { of a stream, } 0 \text { otherwise }\end{array}$ & 0.14 & 0.35 & 0 & 1 \\
\hline Dist2Lake & Parcel distance to lakes and reservoirs in feet & 738 & 477 & 0 & 2,474 \\
\hline Dist2OpenSpace & Parcel distance to open space areas in feet & 998 & 855 & 1 & 3,840 \\
\hline Dist2Trailhead & Building distance to closest trailhead in feet & 10,135 & 5,551 & 378 & 29,948 \\
\hline Dist2Road & Building distance to main road in feet & 756 & 553 & 41 & 3,307 \\
\hline Elevation & Elevation of parcel centroid in feet & 4,944 & 753 & 4,500 & 10,260 \\
\hline \multicolumn{6}{|l|}{ Structure } \\
\hline Age & Age of building in years & 37 & 24 & 1 & 151 \\
\hline Sqft & Finished square footage of the building & 1,884 & 891 & 324 & 11,657 \\
\hline Lotsize & Lot size in acres & 0.17 & 1.82 & 0.01 & 69 \\
\hline CarStorage & 1 if property has car storage, 0 otherwise & 0.93 & 0.25 & 0 & 1 \\
\hline FinishedBasement & $\begin{array}{l}1 \text { if building has a finished basement, } 0 \\
\text { otherwise }\end{array}$ & 0.60 & 0.49 & 0 & 1 \\
\hline NumberBedrooms & The number of bedrooms a building has & 4 & 1 & 0 & 12 \\
\hline NumberFullBaths & The number of full baths a building has & 2 & 0.84 & 0 & 7 \\
\hline Number3qtrBaths & The number of $3 / 4$ baths a building has & 1 & 0.72 & 0 & 9 \\
\hline VeryGoodQuality & $\begin{array}{l}1 \text { if building is listed as very good quality or } \\
\text { above, } 0 \text { otherwise }\end{array}$ & 0.11 & 0.31 & 0 & 1 \\
\hline
\end{tabular}

Note: For the analysis, Price, Dist2Stream, Dist2OpenSpace, Dist2Road, Sqft, and Lotsize were transformed with natural logs. Age was transformed by squaring the variable.

\section{Econometric Results}

Table 3 presents the coefficient estimates and total marginal effects comparing the outcomes of properties inside the SFHA and properties inside the inundation boundary to properties outside both zones. ${ }^{13}$ Specification 1 follows

\footnotetext{
${ }^{13}$ All standard errors are clustered at the floodplain-byinundation-zone-by-census-tract-by-year level. Appendix Table A4 shows that the results are robust to a number of clustering strategies across spatial (census block group, census tract, and municipality) and temporal dimensions (year and year-quarter).
}

from equation [1]: location inside the SFHA is the treatment and we do not account for inundation. As shown in the bottom half of Table 3 , prior to the flood, the average SFHA property is associated with a $6.5 \%$ discount, significantly different from zero. ${ }^{14}$ The discount corresponds to a $\$ 29,062$ discount-in-dollars for the average, nonbasemented property inside the SFHA. To contextualize the results,

\footnotetext{
${ }^{14}$ Percentage change is calculated by taking the exponent of the target coefficient, subtracting one and multiplying by 100 .
} 
Table 3

Flood Risk Effect on Property Prices

\begin{tabular}{|c|c|c|c|}
\hline & $\begin{array}{c}\text { No Inundation } \\
\text { (1) }\end{array}$ & $\begin{array}{c}\text { Inundation as a Control } \\
\text { Variable } \\
(2)\end{array}$ & $\begin{array}{c}\text { Inundation as a } \\
\text { Moderating Variable } \\
\text { (3) }\end{array}$ \\
\hline SFHA & $-0.063 * * *(0.019)$ & $-0.057 * * *(0.020)$ & $-0.042 *(0.023)$ \\
\hline Inundated & & $-0.024(0.023)$ & $0.020(0.027)$ \\
\hline SFHA $\times$ Inundated & & & $-0.083 *(0.046)$ \\
\hline SFHA $\times$ Postflood & $-0.001(0.034)$ & $0.023(0.031)$ & $0.053 *(0.031)$ \\
\hline Inundated $\times$ Postflood & & $-0.061 *(0.036)$ & $-0.017(0.032)$ \\
\hline SFHA $\times$ Inundated $\times$ Postflood & & & $-0.121(0.083)$ \\
\hline Structure and location characteristics & Yes & Yes & Yes \\
\hline Municipality fixed effects & Yes & Yes & Yes \\
\hline Census block group fixed effects & Yes & Yes & Yes \\
\hline Year-quarter fixed effects & Yes & Yes & Yes \\
\hline$R$-squared & 0.775 & 0.776 & 0.776 \\
\hline Observations & 15,056 & 15,056 & 15,056 \\
\hline \multicolumn{4}{|l|}{ Total Marginal Effects } \\
\hline \multicolumn{4}{|l|}{ Preflood } \\
\hline Average inside the SFHA & $-0.063 * * *(0.019)$ & $-0.057 * * *(0.020)$ & \\
\hline Average inside the inundation boundary & & $-0.024(0.023)$ & \\
\hline Inundated inside the SFHA & & & $-0.105 * * *(0.031)$ \\
\hline Near miss & & & $-0.042 *(0.023)$ \\
\hline Inundated outside the SFHA & & & $0.020(0.027)$ \\
\hline \multicolumn{4}{|l|}{ Postflood } \\
\hline Average inside the SFHA & $-0.063 * *(0.032)$ & $-0.034(0.028)$ & \\
\hline Average inside the inundation boundary & & $-0.085 * * *(0.033)$ & \\
\hline Inundated inside the SFHA & & & $-0.190 * * *(0.066)$ \\
\hline Near miss & & & $0.011(0.026)$ \\
\hline Inundated outside the SFHA & & & $0.003(0.025)$ \\
\hline
\end{tabular}

Note: The dependent variable is the natural log of the price. White (1980) robust standard errors in parentheses. Clustering at the floodplainby-inundation-zone-by-census-tract-by-year level. SFHA, Special Flood Hazard Area.

$* p<0.10$; ** $p<0.05$; *** $p<0.01$.

in the month prior to the flood, the average policy holder in Boulder County was insured for $\$ 230,430^{15}$ in flood damage, equating to approximately $\$ 1,500$ to $\$ 2,500$ in yearly premiums, from Table 1 . The net present value of the total insurance payments is $\$ 60,000$ to $\$ 80,000$ calculated into perpetuity assuming a discount rate of $3 \%$. This suggests that the average Boulder County resident did indeed insure against flood risk, but the realized insurance costs were not fully capitalized into the buying price.

After the flood, there was no change in property prices inside the SFHA. The absence of a price decrease stands in contrast with previous literature that found that risk updating from flooding lowers property prices

\footnotetext{
${ }^{15}$ Boulder County insurance data provided via a Freedom of Information Act request.
}

within the SFHA. We speculate that the lack of decrease resulted from the fact that not all properties inside the risky floodplain were directly flooded. Atreya and Ferreira (2015) determined that in Albany, Georgia, the postflood price effect substantially differed within the SFHA, with inundated properties associated with a much larger price discount than noninundated properties. To determine if the same phenomenon is driving the postflood average price premium within the SFHA in Boulder County, a larger and more recent case study, we include inundation in the remaining specifications.

Specification 2 in Table 3 (from equation [3]) provides estimates of the average outcome inside the SFHA while controlling for whether a building was directly flooded. Before the flood, properties that, in the future, would be inundated are not associated 
with a statistically significant discount. After the flood, their average price fell by $6.3 \%$, amounting to a nearly $9 \%$ total postflood discount. The decrease in price likely reflects updated expectations of future flooding and/or costs related to inundation, such as damage. For the average property inside the SFHA, including inundation as a control diminishes the point estimate of the postflood discount to a $3.4 \%$ discount not significantly different from zero.

Specification 2, while accounting for inundation, forces the average effect inside the SFHA to be uniform regardless of whether the property was directly flooded. A more flexible analysis, using triple differences, estimates the price effect for properties inside the SFHA that were inundated separately from SFHA properties that were not inundated (near misses), inundated properties outside the SFHA, and properties subject to neither flood risk signal. Specification 3 from equation [4] does just this. The $11 \%$ preflood discount for SFHA properties that in the future would be inundated was determined by summing the preflood coefficients on inundation, location in the SFHA, and their interaction. After the flood, these properties underwent an average decrease in price, selling for a $21 \%$ discount compared to postflood control properties. The postflood discount was determined by summing all of the relevant flood-related coefficients provided in column 3 .

The total marginal effects for near misses and inundated properties outside the SFHA were calculated similarly. Prior to the flood, properties that would later be near misses were subject to a $4.3 \%$ discount. Given that before the flood there was still only one risk signal-location inside the SFHA - it is not surprising that the preflood discounts for noninundated and inundated SFHA properties are relatively close. After the flood, the near-miss price effect diverged from that of the inundated properties. The average near-miss property increased in price, amounting to a total $1.1 \%$ postflood premium, not significantly different from zero. The difference in price changes between the near misses and inundated properties inside the regulatory floodplain is statistically significant at the $10 \%$ level $(p=0.059)$. Inundated properties outside the SFHA are
Figure 2

Effect of Removing Observations inside the Inundation Boundary on Estimates for Inundated Properties inside the Special Flood Hazard Area (SFHA)

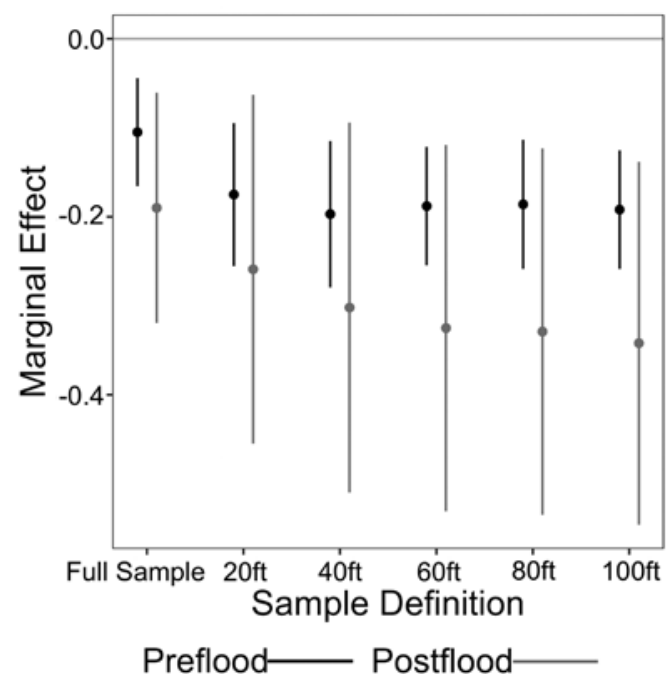

not associated with a major price change after the flood. The average 500-year floodplain property underwent a relative increase in price similar in magnitude to what is experienced by the near misses (Appendix Table A4).

\section{Sensitivity to the Inundation Boundary}

Figure 2 compares the triple-difference results for the full sample against samples whereby properties within a $20(40,60,80$, and 100$)$ foot radius inside of the inundation boundary are dropped. ${ }^{16}$ By incrementally removing the boundary properties, we aim to capture how flooding severity may lead to heterogenous impacts within the SFHA-inundation zone. The assumption is that the flood hazard was less severe close to the inundation boundary than it was far from the inundation boundary (and subsequently close to the sources of the flooding: streams). Figure 2 plots the marginal effects for inundated properties inside the regulatory floodplain and their $95 \%$ confidence intervals. For these properties, the preflood discount increases in absolute value as inun-

\footnotetext{
${ }^{16}$ Full sample: $N=15,056 ; 20 \mathrm{ft}: N=14,921 ; 40 \mathrm{ft}: N$ $=14,902 ; 60 \mathrm{ft}: N=14,886 ; 80 \mathrm{ft}: N=14,871 ; 100 \mathrm{ft}: N=$ 14,839 .
} 


\section{Figure 3}

Residual Plots: Inundated Inside the Special Flood Hazard Area (SFHA), Near Misses, Inundated Outside the SFHA, with 95\% Confidence Intervals (CI)

(a)

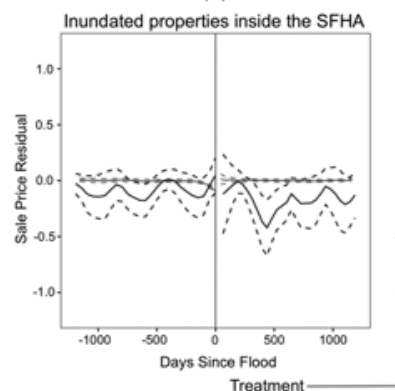

(b)

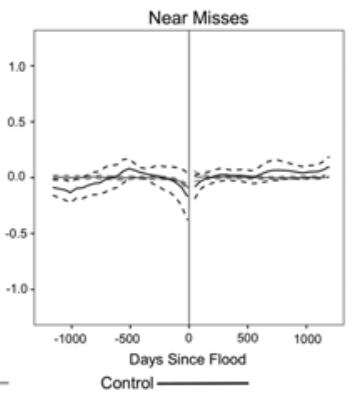

(c)

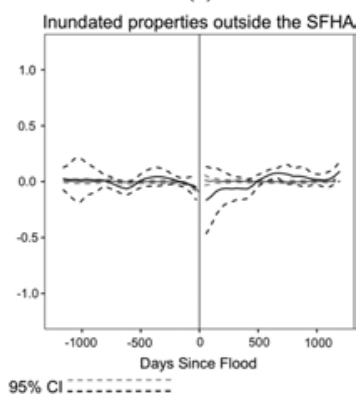

dated properties are incrementally eliminated from the sample, suggesting the presence of preflood heterogenous risk perceptions within the area. Notably, however, despite changes in the preflood discount, the difference between the pre- and postflood discounts also increases, lending support to the hypothesis that inundated properties closer to the source of flooding (and consequently exposed to a more severe flood hazard) underwent a more dramatic price decrease after the flood than properties farther from the source of flooding. Expanding on the flooding severity analysis by combining household-level flood damage data with property sales data is an area for future research. In doing so, researchers may be able to identify the threshold damage levels at which perceived flood risk is enhanced.

\section{Support for Difference-in-Differences Assumptions}

The estimates obtained through difference-in-differences can be interpreted as causal only if the unobserved differences between the treatment and control groups did not change during the study period. In the present study, three statements must be true to satisfy this exchangeability assumption: (1) the timing of the Boulder County flood was exogenous, (2) if there had been no flood, property prices would have evolved in the same way for the treatment groups as the control group, and (3) the composition of property types for treatment and control groups remained stable over the study period.
The first criterion is the easiest to fulfill. By its nature, the timing of a natural disaster event is unpredictable. Figure 3 gives evidence of fulfillment of the second criterion, called the parallel trends assumption. We generated the residuals of a regression of $\log$-prices on the structural and locational controls in addition to the temporal and spatial fixed effects. Epanechikov kernel-weighted local polynomials (with a 180-day bandwidth) were fit onto the residuals and across time for all three treatment groups and the control group. ${ }^{17}$ In all three subfigures the preflood trend for the control properties is (nearly) totally enveloped in the $95 \%$ confidence interval (dashed line) of the flood risk group, suggesting that there are no note-worthy differences in preflood trends between the treatment groups and the control group. Given that the timing of the flood was exogenous, preflood trends should represent the postflood counterfactual.

To get a general sense of how different the property compositions are between the preand postflood periods, we borrow the housing quantity index strategy from McCoy and Walsh (2018). Table 4 reports housing quantity indices by flood risk group. The indices were estimated for each property using weights from a single preflood regression (using all preflood sales) of price on the structural and locational quantities. We then calculated the means and confidence intervals of the housing

\footnotetext{
${ }^{17}$ The 180-day bandwidth was chosen based on temporal considerations associated with accurately capturing changes in housing prices. Similar results are obtained with 90-day and 270-day bandwidths.
} 
Table 4

Testing for Compositional Differences by Treatment Group

\begin{tabular}{|c|c|c|c|}
\hline Treatment Definition & $\begin{array}{l}\text { Mean Preflood } \\
\text { Quantity Index }\end{array}$ & $\begin{array}{l}\text { Mean Postflood } \\
\text { Quantity Index }\end{array}$ & $\begin{array}{c}\text { Welch } t \text {-Test } \\
p \text {-Value }\end{array}$ \\
\hline $\bar{Q}_{\text {SFHA } \times \text { Inundated,Preflood }}-\bar{Q}_{\text {SFHA } \times \text { Inundated,Postflood }}$ & $5.522(5.439,5.606)$ & $5.570(5.469,5.671)$ & 0.476 \\
\hline $\bar{Q}_{\text {SFHA } \times \text { Noninundated.Preflood }}-\bar{Q}_{\text {SFHA }} \times$ Noninundated.Postflood & $5.311(5.262,5.361)$ & $5.322(5.265,5.380)$ & 0.781 \\
\hline $\bar{Q}_{\text {NonSFHA } \times \text { Inundated,Preflood }}-\bar{Q}_{\text {NonSFHA } \times \text { Inundated,Postflood }}$ & $5.296(5.233,5.359)$ & $5.303(5.230,5.378)$ & 0.876 \\
\hline $\bar{Q}_{\text {SFHA } \times \text { Control,Preflood }}-\bar{Q}_{\text {SFHA } \times \text { Control,Postflood }}$ & $5.353(5.344,5.362)$ & $5.343(5.333,5.353)$ & 0.143 \\
\hline
\end{tabular}

Note: The first two columns report the mean quantity index for each risk group, before and after the flood; $95 \%$ confidence intervals surrounding the means are given in parentheses. The last column reports the $p$-values from a Welch two-sample $t$-test comparing the pre- and postflood means. The null hypothesis of the Welch two-sample $t$-test is that the true difference in means is equal to zero.

quantity indices by risk group, pre- and postflood. The $p$-values for $t$-tests of differences in means for each risk group, comparing preflood to postflood, generally support the conclusion that there were no significant changes in group composition.

\section{Discussion}

\section{Preflood Risk Awareness}

The results of the previous section show that there was a statistically significant discount on the average Boulder County SFHA property prior to the flood. Our conclusions are different from the findings of a 2002 Boulder County survey undertaken by Chivers and Flores (2002). The authors found that the majority of survey respondents were not made aware of a property's status in the SFHA until too late in the negotiations for the information to be incorporated into the bargaining process. The fact that a discount is detected in more recent years suggests that flood risk awareness prior to purchasing a property may have increased over time. This is not surprising given Boulder County's recent extensive efforts aimed at increasing flood risk awareness. In the late 2000s, some of Boulder County's communities began promoting flood risk awareness and insurance uptake as a way to improve their standing within FEMA's Community Rating System (CRS). The city of Boulder, for example, joined the CRS in 1992 as a Class 8 community. They improved to a Class 7 in 2008 and a Class 6 in 2012. In early 2013, months prior to the major flood event, the city was awarded a Class 5 rating, decreasing the 100-year floodplain premiums by $15 \%$ compared to the 1992 level (FEMA 2015).

\section{Postflood Risk Awareness}

The majority of previous literature has estimated a decrease in average property prices inside the regulatory floodplain after a flood event (Beltrán, Maddison, and Elliot 2018). Home buyers are likely better able to visualize a flood event and may have a more acute sense of the costs associated with flooding than preflood home buyers. Even if a home buyer did not previously live in the flooded area, real estate agents who experienced the event themselves likely serve as a source of risk information.

This study uncovers a result that deviates from the conclusions of previous literature: the average property inside the SFHA did not experience a decrease in price after the flood. The counterintuitive result can be explained by heterogeneous effects within the regulatory floodplain. While we do estimate a relative price decrease after the flood, it is only for SFHA properties that were directly flooded. SFHA properties outside the inundation boundaries underwent a relative increase in price, with the difference in price changes being statistically different from zero.

Prior to the flood, home buyers were largely exposed to only one flood risk signal type: the regulatory floodplain and its associated insurance requirements. After the flood, the inundation boundaries competed with the SFHA boundaries, often conveying conflicting information about a given property's vulnerability to flooding. For inundated properties inside the SFHA, the 2013 flood was a confirmation, or even heightening, of perceived flood risk. For near misses, where the two risk signals did not overlap, the relative increase in prices suggests the possible in- 
fluence of the availability heuristic: the 2013 event provided a salient example of flood risk that was more easily recalled than the borders of the regulatory floodplain. As a result, nearmiss home buyers in Boulder County updated their flood risk perceptions biased toward the more immediate illustration of flood risk. Alternatively, it may be that home buyers are following a Bayesian learning model, observing where the flooding took place and rationally updating their expectations (Viscusi 1991; Gallagher 2014). Near-miss home buyers may have used the boundaries of the flooding extents to rationally update their flood risk expectations, concluding that their risk level is not as high as the Boulder County floodplain map suggests. Given that Boulder County's floodplain map was 10 years old at the time of the 2013 flood, and significant development (which has the potential to change flood risk hazard) had occurred in the intervening years, there is a strong possibility that at least some discrepancies existed between the county's true flood risk and the regulatory floodplain.

Evidence in support of the availability heuristic or Bayesian learning as a better descriptor of market behavior might come from temporal changes in property prices. In particular, if the relative decrease in the price of inundated properties inside the SFHA after the flood event is only temporary, this would be suggestive evidence in support of the availability heuristic, which relies on near-term recall of events. An event-study analysis of property prices (provided in the Appendix) provides suggestive evidence of such a temporary decrease; however, the relatively small number of observations and the relatively short postflood time horizon inhibit the precision with which we can detect statistical differences in the point estimates over time.

Whether Boulder County home buyers are following the availability heuristic or the Bayesian learning model has implications for the county's social cost of flooding and flood risk. The NFIP has three main elements: hazard identification and mapping, establishing minimum floodplain management criteria for communities, and making flood insurance available to give property owners financial protection. Taken together, the components form a program that, as described in the
NFIP's authorizing legislation, "promote the public interest by encouraging sound land use by minimizing exposure of property to flood losses" (42 U.S. Code $\S$ 4001). In short, the NFIP seeks to minimize the social cost of flooding by fostering internalization of flood risk. When flood risk fails to be capitalized into property prices in flood-prone areas, as in the case of the postflood near misses, the social cost of flooding is not adequately accounted for in the decisions of would-be buyers and developers. Changes in NFIP policies, like stricter penalties for failing to notify home buyers of their flood risk, have the potential to improve efficiency in communities subject to flooding. The change in policy, however, can be welfare increasing only if the areas designated as being vulnerable to flooding are truly at risk. For Boulder County that means that the relative increase in prices in the near-miss areas is problematic only if the 2013 flooding extents were merely a fluke, as in the case of the availability heuristic. If the flooding extents represent true risk, then the relative price increase is rational and efficient.

Following the 2013 flood, the Colorado Water Conservation Board initiated the Colorado Hazard Mapping Program (CHAMP) to re-map the SFHA of the most affected areas. While for the majority of the county the re-mapping effort appears to be only expanding the SFHA, in some areas, particularly those with many near-miss properties, the area of the SFHA was reduced. ${ }^{18}$ This implies that the impact of the relative price increase for the near misses is mixed: in some parts of the county the price increase is a rational response to true flood risk, while in other places policies that encourage risk internalization would bring expected flooding costs closer to efficient levels. While not widely publicized, CHAMP maps first became available for public consumption in the winter of 2017.

\section{Conclusion}

This paper examines the effect of the NFIP in combination with an actual flood event on

\footnotetext{
${ }^{18}$ Boulder County, Floodplain: BC Regulated, available at http://gis-bouldercounty.opendata.arcgis.com/data sets/9bd4fe1762434e05b1c5ddbf4753f1a1_0.
} 
sales prices in the Boulder County housing market. We estimate a $6.5 \%$ discount inside the regulatory floodplain prior to the 2013 flood. After the flood, properties that were both directly flooded and located in the SFHA were associated with a $21 \%$ discount. Properties outside the inundation boundaries but inside the SFHA underwent a relative increase in price, selling for a postflood premium not significantly different from zero, while inundated properties outside the regulatory floodplain were associated with essentially no postflood price change. The difference in price changes is significantly different from zero at the $10 \%$ level.

Our results are suggestive of the availability heuristic and/or a Bayesian learning model. In the former, home buyers bias their flood risk perceptions toward an example that can easily be brought to mind: the 2013 flood. In the latter, home buyers rationally update their risk perceptions using the 2013 flooding extents. If the flooding extents represent true differences in risk within the regulatory floodplain, then the divergence in prices is welfare increasing.

Studies like this one can help policy makers cope with changing flood risk. In the American Mountain West, heavy, prolonged rainfall events that trigger rapid snowmelt are expected to double in frequency by the end of the century due to anthropogenic warming (Musselman et al. 2018). The increase in flood hazard is accompanied by escalating exposure: in the past century, the Boulder County population has grown five times faster than that of the United States and is currently among the fastest growing with a growth rate of nearly $3 \%$ per year. To keep flood risk in check, policy makers must focus on containing the county's exposure and vulnerability to flood damages. Understanding how experience with the 2013 flood influences flood risk perception can help policy makers in encouraging flood risk recognition to lower future costs of flooding. Examining the extent to which the heterogenous postflood price effects within the regulated floodplain can be attributed to the availability heuristic versus a Bayesian learning model will be essential for maximizing the benefits of such risk awareness campaigns in the future. In addition, a better understanding of behavioral responses to updated flood risk maps will enable planners to understand the economic trade-offs associated with increasing the frequency of such re-mapping efforts, particularly in rapidly developing areas such as Boulder County. Conducting surveys of home buyers may help to better elucidate the full range of behavioral responses to flood events; and how these responses may be moderated by updated flood risk maps is a fruitful area for future research.

\section{Acknowledgments}

This research was initiated while Hannah Hennighausen was a visiting student at Colorado State University's Department of Agricultural and Resource Economics. The research by Hannah Hennighausen was funded by the Young Scientist Fund of the Styrian Sparkasse and the Austrian Science Fund (FWF) under research grant W1256-G15: Doctoral Program Climate Change-Uncertainties, Thresholds and Coping Strategies. We are grateful for additional support from alpS Innsbruck and comments by the participants of the 2017 Canadian Resource and Environmental Economics Conference, the 6th World Congress of Environmental and Resource Economics, and the University of Colorado Environmental and Resource Economics Workshop. Many thanks also to Birgit Bednar-Friedl and other researchers at the Wegener Center, University of Graz Economics Department, and Colorado State University for their valuable critiques of this work.

\section{References}

American Institutes for Research. 2005. A Chronology of Major Events Affecting the National Flood Insurance Program. A report for the Federal Emergency Management Agency. Washington, DC: Federal Emergency Management Agency. Available at https://www.fema.gov/medialibrary-data/20130726-1602-20490-7283/nfip_ eval_chronology.pdf.

Atreya, Ajita, and Susana Ferreira. 2015. "Seeing Is Believing? Evidence from Property Prices in Inundated Areas." Risk Analysis 35 (5): 828-48.

Atreya, Ajita, Susana Ferreira, and Warren Kriesel. 2013. "Forgetting the Flood? An Analysis 
of the Flood Risk Discount over Time." Land Economics 89 (4): 577-96.

Beltrán, Allan, David Maddison, and Robert J. R. Elliot. 2018. "Is Flood Risk Capitalised into Property Values?" Ecological Economics 146: 668-85.

. 2019. "The Impact of Flooding on Property Prices: A Repeat-Sales Approach.” Journal of Environmental Economics and Management 95: 62-86.

Bernstein, Asaf, Matthew Gustafson, and Ryan Lewis. 2019. "Disaster on the Horizon: The Price Effect of Sea Level Rise." Journal of Financial Economics 134 (2): 253-72.

Bin, Okmyung, and Craig E. Landry. 2013. "Changes in Implicit Flood Risk Premiums: Empirical Evidence from the Housing Market." Journal of Environmental Economics and Management 65 (3): 361-76.

Bin, Okmyung, and Stephen Polasky. 2004. "Effects of Flood Hazards on Property Values: Evidence before and after Hurricane Floyd." Land Economics 80 (4): 490-500.

Black, Sandra E. 1999. "Do Better Schools Matter? Parental Valuation of Elementary Education." Quarterly Journal of Economics 114 (2): 577-99.

Boulder County. 2017. Boulder County Wildfire Zone Map. Boulder, CO: Boulder County. Available at https://assets.bouldercounty.org/ wp-content/uploads/2017/02/wildfire-zonemap.pdf.

Carbone, Jared C., Daniel G. Hallstrom, and V. Kerry Smith. 2006. "Can Natural Experiments Measure Behavioral Responses to Environmental Risks?" Environmental and Resource Economics 33 (3): 273-97.

Chivers, James, and Nicholas E. Flores. 2002. "Market Failure in Information: The National Flood Insurance Program" Land Economics 78 (4): 515-21.

CRED (Centre for Research on the Epidemiology of Disasters). 2015. The Human Cost of Weather-Related Disasters, 1995-2015. Louvain, Belgium: Centre for Research on the Epidemiology of Disasters, United Nations Office for Disaster Risk Reduction.

Cropper, Maureen, Leland B. Deck, and Kenneth McConnell. 1988. "On the Choice of Functional Form for Hedonic Price Functions." Review of Economics and Statistics 70 (4): 668-75.

Daniel, Vanessa E., Raymond J.G.M. Florax, and Piet Rietvald. 2009. "Flooding Risk and Housing Values: An Economic Assessment of Envi- ronmental Hazard." Ecological Economics 69 (2): 355-65.

FEMA (Federal Emergency Management Agency). 2015. Reducing Losses through Higher Regulatory Standards. Washington, DC: Federal Emergency Management Agency.

- 2016. Publication 1. Washington, DC: Federal Emergency Management Agency (FEMA). Available at https://www.fema.gov/ media-library-data/1462196227387-c10c40e5 85223d22e2595001e50f1e5c/Pub1_04-07.pdf.

. 2018. Flood Insurance Manual, Effective April 1 2018. Washington, DC: Federal Emergency Management Agency.

Gallagher, Justin. 2014. "Learning about an Infrequent Event: Evidence from Flood Insurance Take-up in the United States." American Economic Journal: Applied Economics 6 (3): 206-33.

GAO (U.S. Government Accountability Office). 2011. Flood Insurance: Public Policy Goals Provide a Framework for Reform. 2011. Washington, DC: U.S. Government Accountability Office.

Gochis, David, Russ Schumacher, Katja Friedrich, Nolan Doesken, Matt Kelsch, Juanzhen Sun, Kyoko Ikeda, Daniel Lindsey, Andy Wood, Brenda Dolan, et al. 2015. "The Great Colorado Flood of September 2013." Bulletin of the American Meteorological Society 96 (9): 1461-87.

Gopalakrishnan, Sathya, Martin D. Smith, Jordan M. Slott, and A. Brad Murray. 2011. "The Value of Disappearing Beaches: A Hedonic Pricing Model with Endogenous Beach Width." Journal of Environmental Economics and Management 61 (3): 297-310.

Hallstrom, Daniel G., and V. Kerry Smith. 2005. "Market Responses to Hurricanes." Journal of Environmental Economics and Management 50 (3): 541-61.

Harrison, David M., Greg T. Smersh, and Arthur L. Schwartz. 2001. "Environmental Determinants of Housing Prices: The Impact of Flood Zone Status." 21 (1-2): 3-20.

Holway, James, and Raymond Burby. 1990. "The Effects of Floodplain Development Controls on Residential Land Values." Land Economics 66 (3): 259-71.

Kousky, Carolyn. 2010. "Learning from Extreme Events: Risk Perceptions after the Flood." Land Economics 86 (3): 395-422.

McCoy, Shawn J., and Randall P. Walsh. 2018. "Wildfire Risk, Salience and Housing De- 
mand." Journal of Environmental Economics and Management 91: 203-28.

McCoy, Shawn J., and Xiaoxi Zhao. 2018. "A City under Water: A Geospatial Analysis of Storm Damage, Changing Risk Perceptions and Investment in Residential Housing." Journal of the Association of Environmental and Resource Economics 5 (3): 301-30.

Meldrum, James. 2015. "Floodplain Price Impacts by Property Type in Boulder County, Colorado: Condominiums versus Standalone Properties." Environmental and Resource Economics 64 (4): 725-50.

Michel-Kerjan, Erwann O. 2010. "Catastrophe Economics: The National Flood Insurance Program." Journal of Economic Perspectives 24 (4): $165-86$.

Musselman, Keith N., Flavio Lehner, Kyoko Ikeda, Martyn P. Clark, Andreas F. Prein, Changhai Liu, Mike Barlage, and Roy Rasmusson. 2018. "Projected Increases and Shifts in Rain-onSnow Flood Risk over Western North America." Nature Climate Change 8 (9): 808-12

Ortega, Francesco, and Süleyman Taşpinar. 2018. "Rising Sea Levels and Sinking Property Values: Hurricane Sandy and New York's Housing Market." Journal of Urban Economics 106: 81-100.

Palmquist, Raymond B. 1982. "Measuring Environmental Effects on Property Values without Hedonic Regressions.” Journal of Urban Economics 11 (3): 333-47.

Pettem, Silvia. 2016. Boulder's Floods and Flood Management: Past and Present. Boulder, CO: Education Department, City of Boulder's Public Works/Utilities.

Ridker, Ronald G., and John A. Henning. 1967. "The Determinants of Residential Property Values with Special Reference to Air Pollution." Review of Economics and Statistics 49 (2): 246-57.

Rosen, Sherwin. 1974. "Hedonic Prices and Implicit Markets: Product Differentiation in Pure Competition." Journal of Political Economy 82 (1): 34-55.
Schultz, Steven D., and Pat M. Fridgen. 2001. "Floodplains and Housing Values: Implications for Flood Mitigation Projects." Journal of the American Water Resources Association 37 (3): 595-603.

Severen, Christopher, Christopher Costello, and Olivier Deschenes. 2018. "A Forward-Looking Ricardian Approach: Do Land Markets Capitalize Climate Change Forecasts?" Journal of Environmental Economics and Management 89: 235-54.

Skantz, Terrance, and Thomas Strickland. 1987. "House Prices and a Flood Event: An Empirical Investigation of Market Efficiency." Journal of Real Estate Research 2 (2): 75-83.

Tanaka, Shinsuke, and Jeffrey Zabel. 2018. "Valuing Nuclear Energy Risk: Evidence from the Impact of the Fukushima Crisis on U.S. House Prices." Journal of Environmental Economics and Management 88: 411-26.

Tversky, Amos, and Daniel Kahneman. 1973. "Availability: A Heuristic for Judging Frequency and Probability." Cognitive Psychology 5 (2): 207-32.

USGS (U.S. Geological Survey). 2006. Flood Hazards: A National Threat. 2006. Reston, VA: U.S. Geological Survey.

Viscusi, W. Kip. 1991. "Economic Theories of Decision Making under Uncertainty: Implications for Policy Analysis." In Policy Analysis and Economics: Developments, Tensions, Prospects, ed. David L. Weimer, 85-109. Boston: Kluwer Academic Publishers.

Walls, Margaret A., Carolyn Kousky, and Ziyan Chu. 2015. "Is What You See What You Get? The Value of Natural Landscape Views." Land Economics 91 (1): 1-19.

White, Gilbert F. 1958. "Changes in Urban Occupancy of Flood Plains in the United States." Research Paper No. 57. Chicago: Department of Geography, University of Chicago.

White, Halbert. 1980. "A Heteroskedasticity-Consistent Covariance Matrix Estimator and a Direct Test for Heteroskedasticity." Econometrica 48 (4): 817-38. 